\title{
The Hudson-Stahli Line II: A Comparison of Properties in Eyes with and without Long-term Contact Lens Wear
}

\author{
GEOFFREY E. ROSE and MICHAEL J. LAVIN \\ London
}

\begin{abstract}
Summary
The eyes of 98 long-term contact lens wearers and 342 subjects not wearing contact lenses were examined for the presence of Hudson-Stahli lines, using slit-lamp biomicroscopy. The period of contact lens wear ranged from 2 to 25 years, all subjects using contact lenses for refractive reasons only. The incidence of HudsonStahli lines in contact lens wearers was not significantly different from that of control subjects in the same decades. Contact lenses appear, however, variably to alter the characteristics of the Hudson-Stahli line. Results from a group of 4 unilateral lens wearers, from 94 bilateral lens wearers and from studies of the morphology of the line suggest that contact lens wear is associated with a relative reduction of length and density of the line and also with a broadening and, more rarely, displacement of it. In eyes with brown or green irides, the attenuation of length and density by contact lens wear obscures the normal increases seen with age; in this subgroup of contact lens wearers, both factors appear to be almost constant from the third to sixth decades of life.
\end{abstract}

The position and configuration of the Hudson-Stahli line have been attributed variously to properties of either the exposed tear film and the inferior tear line ${ }^{1.2}$ or to the exposed epithelium in the interpalpebral fissure. ${ }^{3}$ It is because the long-term wear of contact lenses would be expected to profoundly influence both of these factors, that a study of such a group of subjects was undertaken.

\footnotetext{
Material and Methods

Using slit-lamp biomicroscopy, 98 patients attending an Ophthalmic Accident and Emergency department were examined for the presence of Hudson-Stahli lines; none had corneal disease and none were using long-term ocular medication. All
}

of these subjects had used refractive contact lenses for over two years (range 2 to 25 years); types of lenses used included hard corneal, gas-permeable or soft and some subjects had used two varieties sequentially. The Hudson-Stahli lines were graded for length and density, using methods described previously ${ }^{4}$ and the morphology and position of the lines were recorded.

To provide a comparative sample, a control group of subjects without contact lens wear was examined; these subjects formed part of a previous report. ${ }^{4}$ In view of the subjective and somewhat arbitrary nature of the gradings for length and density of the line, the analysis of results was semiquantitative and complex statistical analyses were not used.

\section{Results}

Four of the 98 subjects were unilateral contact 
Table I. Details of Hudson-Stahli lines in four unilateral contact lens wearers

\begin{tabular}{|c|c|c|c|c|}
\hline No. & Age & $\begin{array}{l}\text { Iris } \\
\text { Colour }\end{array}$ & Ocular status & $\begin{array}{c}\text { Hudson-Stahli line } \\
\text { (Length/Density) }\end{array}$ \\
\hline 1 & 50 & Blue & $\begin{array}{l}\text { Right aphakic, } \\
\text { (hard lens) } \\
\text { Left phakic }\end{array}$ & $\begin{array}{l}\text { (Absent) } \\
<\frac{1}{4} \text {, Faint }\end{array}$ \\
\hline 2 & 59 & Blue & $\begin{array}{l}\text { Right phakic } \\
\text { Left aphakic, } \\
\text { (hard lens) }\end{array}$ & $\begin{array}{l}>\frac{1}{2}, \text { Dense } \\
\frac{1}{4}-\frac{1}{2}, \text { Faint }\end{array}$ \\
\hline 3 & 57 & Brown & $\begin{array}{l}\text { Right aphakic, } \\
\text { (hard lens) } \\
\text { Left aphakic } \\
\text { (IOL) }\end{array}$ & $\begin{array}{c}\text { (Absent) } \\
>\frac{1}{2}, \text { Moderate }\end{array}$ \\
\hline 4 & 66 & Brown & $\begin{array}{l}\text { Right aphakic, } \\
\text { (soft lens) } \\
\text { Left phakic }\end{array}$ & $\begin{array}{c}<\frac{1}{4} \text {, Faint } \\
>\frac{1}{2} \text {, Moderate }\end{array}$ \\
\hline
\end{tabular}

lens wearers and were excluded from the main series; the details of these aphakic patients are presented in Table I.

Amongst the remaining 94 subjects, 54 $(57 \%)$ had blue/grey irides and $40(43 \%)$ had the more heavily pigmented brown/green irides; these proportions compare well with the control group of 342 subjects (59\% blue/ grey and $41 \%$ brown/green).

The ages of the contact lens wearers ranged from 18 to 65 years (blue/grey irides) and 19 to 69 years (brown/green). Because of the bias towards contact lens wear in the younger decades, all comparisons between contact lens wearers and the control group were agerelated, being based on comparative decades.

The incidence of the line varies with age, from $0 \%$ to $59 \%$ in contact lens wearers with blue/grey eyes and $0 \%$ to $100 \%$ in those with brown/green eyes (Table II); the comparative extremes in control subjects are 18\%-83\% and $25 \%-84 \%$, respectively.

The mean values for the gradings of length or density (or the combined 'length/density' score), within involved eyes are summarised in Table III; the Table allows an age-related comparison of values in contact lens wearers and in 'normal' control eyes.

Differences in the configuration of the Hudson-Stahli line in contact lens wearers and control subjects, whilst almost impossible to

Table II Incidence of Hudson-Stahli line in the corneas of 94 long term contact lens wearers and 342 control subjects, classified by age and Iris colour. The incidence is expressed both as a fraction and as a percentage (in brackets) within each subgroup

\begin{tabular}{|c|c|c|c|c|c|c|c|}
\hline \multirow[b]{2}{*}{ Iris colour } & \multirow[b]{2}{*}{ Subgroup } & \multicolumn{6}{|c|}{ Age group (years) } \\
\hline & & $<20$ years & 20-29 years & 30-39 years & 40-49 years & $50-59$ years & $60-69$ years \\
\hline Blue/grey & $\begin{array}{l}\text { Contact lens } \\
\text { Wearers } \\
\text { Controls }\end{array}$ & $\begin{array}{c}0 / 2(0 \%) \\
4 / 22(18 \%)\end{array}$ & $\begin{array}{l}12 / 44(27 \%) \\
26 / 76(35 \%)\end{array}$ & $\begin{array}{l}18 / 32(56 \%) \\
29 / 72(40 \%)\end{array}$ & $\begin{array}{l}13 / 22(59 \%) \\
42 / 64(66 \%)\end{array}$ & $\begin{array}{c}0 / 4(0 \%) \\
79 / 98(79 \%)\end{array}$ & $\begin{array}{c}0 / 4(0 \%) \\
58 / 70(83 \%)\end{array}$ \\
\hline Brown/Green & $\begin{array}{l}\text { Contact lens } \\
\text { Wearers } \\
\text { Controls }\end{array}$ & $\begin{array}{c}0 / 6(0 \%) \\
5 / 20(25 \%)\end{array}$ & $\begin{array}{l}24 / 36(67 \%) \\
24 / 42(57 \%)\end{array}$ & $\begin{array}{l}21 / 26(81 \%) \\
51 / 76(67 \%)\end{array}$ & $\begin{array}{c}4 / 4(100 \%) \\
51 / 62(82 \%)\end{array}$ & $\begin{array}{c}6 / 6(100 \%) \\
37 / 44(84 \%)\end{array}$ & $\begin{array}{c}1 / 2(50 \%) \\
28 / 38(74 \%)\end{array}$ \\
\hline
\end{tabular}

Table III Characteristics of Hudson-Stahli line in contact lens wearers. Figures in brackets refer to mean values from a control group with normal eyes

\begin{tabular}{|c|c|c|c|c|c|c|}
\hline \multirow[b]{2}{*}{ Grading } & \multirow[b]{2}{*}{ Iris colour } & \multicolumn{5}{|c|}{ Age group (years) } \\
\hline & & 20-29 years & 30-39 years & 40-49 years & $50-59$ years & $60-69$ years \\
\hline Mean combined & Blue/grey & $1.67(1.67)$ & $2.67(1.79)$ & $3.00(2.83)$ & $-\quad(3.80)$ & $-\quad(4.19)$ \\
\hline $\begin{array}{l}\text { Length and density } \\
\text { Scoring }\end{array}$ & Brown/green & $2.92(2.58)$ & $2.43(3.41)$ & $2.25(3.02)$ & $2.33(4.41)$ & $1.00(5.14)$ \\
\hline $\begin{array}{l}\text { Mean } \\
\text { Length }\end{array}$ & Blue/grey & $1.42(1.73)$ & $2.17(1.69)$ & $2.23(2.40)$ & $-\quad(2.63)$ & $-\quad(2.62)$ \\
\hline Grading & Brown/green & $2.17(2.58)$ & $2.43(2.49)$ & $2.25(2.51)$ & $2.33(2.84)$ & $1.00(2.79)$ \\
\hline $\begin{array}{l}\text { Mean } \\
\text { Density }\end{array}$ & Blue/grey & $1.17(1.08)$ & $1.17(1.07)$ & $1.31(1.17)$ & $-\quad(1.41)$ & $-\quad(1.55)$ \\
\hline Grading & Brown/green & $1.29(1.00)$ & $1.00(1.31)$ & $1.00(1.18)$ & $1.00(1.54)$ & $1.00(1.79)$ \\
\hline
\end{tabular}


quantitate, have been observed by the authors and are described in the discussion.

\section{Discussion}

The small group with unilateral contact lens wear for aphakia demonstrate a marked discordance of Hudson-Stahli line between the two eyes of each pair (Table I). The probability of four consecutive discordances in "normal" eyes is approximately $0.16 \%$ (based on a $20 \%$ discordance rate-Ref 4 ); this significantly low probability implying the asymmetry to be either a property of the contact lens or the cataract extraction. In three patients (Nos 1, 2 and 4) there was both aphakia and contact lens wear in the eye with a shorter and less dense line; in one case (No 3 ), however, the patient was bilaterally aphakic but still showed the marked reduction of Hudson-Stahli line in the eye wearing a contact lens. Age adjusted comparisons of the line in contact lens wearers and controls also suggests that it is the contact lens, rather than the aphakia, which affects the properties of the line.

The small differences between the observed incidences of Hudson-Stahli lines in lens wearers and controls within various subgroups of age and iris colour (Table II) do not reach statistical significance (chi square testing at $5 \%$ probability level), although in both groups there is a rising incidence with age.

Considering eyes in which the line is present, the combined 'length/density' scores tend to be marginally higher in lens wearers with blue eyes than in the control group and in both groups the score increases with age (Table III). It is probable that the slightly higher combined 'length/density' score in blue-eyed wearers of contact lenses is attributable to a slightly increased density of the lines and the increasing score with age seems related to increasing length (Table III). In contrast, the mean score in brown-eyed contact lens wearers is almost constant with age and, even into the sixth decade, tends to have the (lower) values characteristic of control eyes in their third decade; both the density and length of line in this subgroup of lens wearers are slightly lower than those of the control group.

Irrespective of iris colour, the highest mean scores for contact lens wearers are 3.00 for combined 'length/density' score, 2.43 for length score and 1.31 for density score, this contrasting with the highest values in the control group (5.14, 2.84 and 1.79, respectively). This contrast, together with the evidence from unilateral lens wearers, suggests that contact lens wear causes an attenuation of both the density and the length of the Hudson-Stahli line; in addition, in brown eyes this attenuation seems to obscure the normal age-related increase of length and density.

Whereas the Hudson-Stahli line in normal eyes is generally either an irregular single line or multiple ramifying lines, often superimposed on a broad (approximately $1-2 \mathrm{~mm}$ ) band of very fine pigmentation, ${ }^{5}$ that in contact lens wearers frequently forms a much broader $(3-5 \mathrm{~mm})$ zone of extremely faint pigmentation. Another phenomenon, not seen in a series of 550 subjects, ${ }^{4}$ was the displacement of the Hudson-Stahli line from its usual position to lie on the upper half of the corneal epithelium in two contact lens wearers; in both cases the line formed a broad zone of faint pigmentation.

From observations during the present study, therefore, it would appear that longterm contact lens wear alters, rather variably, the morphology, length and density of the Hudson-Stahli line. The line would reasonably be expected to vary between different wearers of contact lenses-the alterations of tear film and epithelial dynamics by contact lenses of different types, different profiles and different movement characteristics would all act to increase the variability of the line in such a group.

Further valuable information could be gained by the examination of contact lens wearers using lenses in one eye for refractive reasons only and also by the sequential examination of patients discontinuing contact lens wear.

\section{References}

${ }^{1}$ Norn MS. Hudson-Stahli's line of cornea. II. Aetiological studies. Acta Ophthalmol 1968; 46: 119-28.

${ }^{2}$ Barraquer-Somers E, Chan CC, Green WR. Corneal epithelial iron deposition. Ophthalmology 1983; 90: 729-34. 
${ }^{3}$ Gass JD. The iron lines of the superficial cornea. Hudson-Stahli line, Stocker's line and Fleischer's ring. Arch Ophthalmol 1964; 71: 348-58.

${ }^{4}$ Rose GE, Lavin MJ. The Hudson-Stahli line I. An Epidemiological Study. Eye 1987 (In Press).
${ }^{5}$ Rose GE, Lavin MJ. The Hudson-Stahli line III. Observations on Morphology, a Critical Review of Ætiology and a Unified theory for the Formation of Iron lines of the Corneal Epithelium. Eye 1987 (In Press). 